\title{
'Too much of a coincidence': identical twins with exertional heatstroke in the same race
}

\author{
R Smith, ${ }^{1} \mathrm{~N}$ Jones, ${ }^{1}$ D Martin, ${ }^{2}$ C Kipps ${ }^{3}$
}

${ }^{1}$ Department of Sport and Exercise Medicine, Nuffield Orthopaedic Centre, Oxford University Hospitals NHS Trust, Oxford, Oxon, UK ${ }^{2}$ UCL Centre for Altitude, Space and Extreme Environment Medicine, Institute of Sport, Exercise and Health (ISEH), London, UK ${ }^{3}$ Division of Surgery and Interventional Sciences, Institute of Sport, Exercise and Health (ISEH), London, UK

Correspondence to Dr R Smith,

ralph.smith@doctors.org.uk

Accepted 16 January 2016

\section{CrossMark}

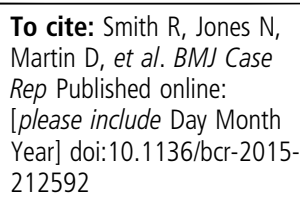

\begin{abstract}
SUMMARY
This report discusses a unique case of monozygotic male twins who both collapsed with exertional heat stroke (EHS) during the same marathon in relatively cool conditions. The twins were official race pacers in a popular city marathon held in the early spring in the UK. Both recovered uneventfully due to the prompt recognition of EHS and use of aggressive cooling measures, which prevented life-threatening complications. The case illustrates that EHS is a complex illness with a possible genetic predisposition, which can occur among runners even in cooler conditions. This link is explored together with the influence of their role as race pacers and the additional backpack worn in the development of EHS.
\end{abstract}

\section{BACKGROUND}

Mass-participation endurance events are increasingly popular worldwide. The gruelling 26.2-mile $(42.2 \mathrm{~km})$ marathon is one of the most renowned long distance events and participation is not without risk. Exertional heat stroke (EHS) is a potentially life-threatening illness presenting in the collapsed runner and is one of the three most common causes of sudden death in athletes. ${ }^{1}$

EHS is defined as a central neurological dysfunction associated with an elevated core temperature above $40^{\circ} \mathrm{C}$ during or after exercise. ${ }^{2}$ The collapsed runner presents in a confused, drowsy or often unresponsive state, usually in hot humid conditions. While environmental conditions play a significant role, ${ }^{3}$ there are reports from cooler environments, ${ }^{45}$ suggesting a variation in an individual's susceptibility. Predisposing factors such as insufficient heat acclimatisation, inadequate physical fitness or transient factors such as current febrile illness and sleep deprivation have been found to be influential. ${ }^{6}$ Links to malignant hyperthermia, an inherited skeletal muscle disorder, suggests a potential genetic predisposition. ${ }^{7}$ Running intensity may also play a significant role with several reports of athletes diagnosed with EHS who were unwilling to curtail their workload. ${ }^{489}$ The loss of thermoregulation in EHS can lead to potentially fatal complications such as circulatory collapse, multiorgan dysfunction and disseminated intravascular coagulation. ${ }^{10}$ Prompt recognition by specifically measuring core temperature as peripheral is often falsely reassuring, and immediate cooling is vital to prevent deaths. ${ }^{11}$

We describe a unique case of monozygotic twins who collapsed with a diagnosis of EHS during the same large city marathon in relatively cool conditions in early spring in the UK. They were official race pacers. This report examines the genetic predisposition to EHS and the potential influence of their role as race pacers.

\section{CASE PRESENTATION}

Both runners, monozygotic male twins aged 26 years (confirmed in medical record and Twin Zygosity Questionnaires), were official race pacers instructed to maintain a constant pace to assist fellow runners who were aiming for a particular finishing time. Pacers, who ran in pairs, carried a $2.5 \mathrm{~kg}$ backpack with a flag attachment. Neither runner had performed this before, and nor had they trained with the backpack.

Both twins had completed several marathons with personal best times under $4 \mathrm{~h}$ and were experienced runners. Their training was similar to their previous marathon preparation, starting 15 weeks earlier with a gradual increase in their mileage on individual runs. They both followed similar training programmes. They did not train together and all training took place within the UK. Prior to the marathon, both had completed runs over $35 \mathrm{~km}$ within $3 \mathrm{~h} 45 \mathrm{~min}$. Neither had any significant medical history or previous surgery nor suffered from EHS in the past. They did not take any regular medications or supplements. No family members had a history of malignant hyperthemia or complications following general anaesthesia. Their ethnic origin was white British. Both twins had a body mass index of 23 (weight $71 \mathrm{~kg}$, Height $1.71 \mathrm{~m}$ ). Prior to the start of the race, neither took any medication including paracetamol or non-steroidal anti-inflammatory drugs or any supplements. They denied any sleep deprivation and felt in good health and well hydrated prior to the start.

The race was held in early spring in the south of the UK. Conditions on race day were described as warm, dry and without rainfall. During the time of the race (between 10:00 AM and 17:00 $\mathrm{PM}$ ), the average ambient temperature (AAI) was $12.5^{\circ} \mathrm{C}$, average relatively humidity (ARH) $44 \%$ and Wet-bulb globe temperature (WBGT) $8.7^{\circ}$ C. The maximum ambient temperature was $15.2^{\circ}$ C (highest recorded peak temperature for this event was $22.2^{\circ} \mathrm{C}$ ). The mean AAI over the past 5 years on race day was $14.6^{\circ} \mathrm{C}$, ARH $52 \%$ and WBGT $11.2^{\circ} \mathrm{C}$. The race start time was $10.00 \mathrm{~h}$ with over 38000 competitors ranging from amateur to world-class elite. Twin A's planned completion time was $4 \mathrm{~h} 30 \mathrm{~min}$ while for twin B it was $4 \mathrm{~h} 45 \mathrm{~min}$. 
Table 1 Shows the split times of the runners

\begin{tabular}{|c|c|c|c|c|c|c|c|c|}
\hline \multirow[b]{2}{*}{ Distance (km) } & \multicolumn{4}{|c|}{ Twin A estimated finish: 04:33:21 (planned pace) } & \multicolumn{4}{|c|}{ Twin B estimated finish: 04:45:27 (planned pace) } \\
\hline & Time & Diff & $\min / k m$ & $\mathrm{~km} / \mathrm{h}$ & Time & Diff & $\mathrm{min} / \mathrm{km}$ & $\mathrm{km} / \mathrm{h}$ \\
\hline 5 & $00: 31: 34$ & 31:34:00 & 06:19 & 9.5 & $00: 33: 27$ & $33: 27: 00$ & 06:42 & 8.97 \\
\hline 10 & 01:03:52 & 32:18:00 & $06: 28$ & 9.29 & 01:08:11 & $34: 44: 00$ & 06:57 & 8.64 \\
\hline 15 & 01:36:04 & 32:12:00 & 06:27 & 9.31 & 01:41:21 & 33:10:00 & 06:38 & 9.05 \\
\hline 20 & 02:08:18 & 32:14:00 & 06:27 & 9.31 & 02:15:14 & 33:53:00 & 06:47 & 8.85 \\
\hline 25 & $02: 41: 12$ & 33:06:00 & $06: 39$ & 9.04 & $02: 49: 19$ & $34: 05: 00$ & $06: 52$ & 8.75 \\
\hline \multirow[t]{2}{*}{30} & $03: 14: 21$ & $33: 09: 00$ & $06: 38$ & 9.05 & $03: 22: 57$ & $33: 38: 00$ & $06: 44$ & 8.92 \\
\hline & \multicolumn{4}{|c|}{$\begin{array}{l}30.5 \mathrm{~km} \text { collapsed } \\
\text { Estimated total calories burnt: } \\
2212 \mathrm{kcal}\end{array}$} & \multicolumn{4}{|c|}{$\begin{array}{l}33.7 \mathrm{~km} \text { collapsed } \\
\text { Estimated total calories burnt: } 2444 \mathrm{kcal}\end{array}$} \\
\hline
\end{tabular}

Diff, Difference in time between $5 \mathrm{~km}$ intervals.

Approximately $3 \mathrm{~h}$ into the race, twin A had reached 17 miles $(27.3 \mathrm{~km})$ and was struggling to keep up with his pacing partner (table 1$)$. At 19 miles $(30.5 \mathrm{~km}), 3 \mathrm{~h} 17 \mathrm{~min}$ into the race, he collapsed. He was taken by stewards to the nearest medical tent where he was noted to be confused and drowsy but responsive to verbal command. His skin was cool, sweaty and pale in appearance (table 2). A rectal temperature of $41.1^{\circ} \mathrm{C}$ confirmed the diagnosis of EHS and rapid cooling measures were started including stripping of the athlete, dousing in cold water and wrapping him in a cold wet sheet. As his level of consciousness improved, he developed severe muscle cramps in both legs. Within $30 \mathrm{~min}$, his rectal temperature had dropped to $38.2^{\circ} \mathrm{C}$, he was alert and orientated and the cramps had resolved. He was discharged just over $1 \mathrm{~h}$ post presentation. Owing to the clinical presentation and improvement with cooling measures, serum sodium levels were not measured.

Twin B had also started to struggle with his set pace and collapsed at mile $21(33.7 \mathrm{~km}), 3 \mathrm{~h} 45 \mathrm{~min}$ into the race. On arrival at the medical tent, he was also confused but responding to verbal command. Recorded observations showed a heart rate of 105 , a respiratory rate of 28 and his rectal temperature was $40.7^{\circ} \mathrm{C}$. Identical cooling methods were undertaken (table 2) and he was discharged within $1 \mathrm{~h}$ following improvement in his condition.
The annual incidence of EHS at this marathon has not as yet been published; however, including the individuals in this report, there were at least 14 recorded cases during this marathon.

Both athletes took a week of rest before gradually returning to running. Three months later, Twin A completed a 69 mile ultra-endurance run (peak temperature of $17^{\circ} \mathrm{C}$ ) uneventfully while Twin B successfully completed a $10 \mathrm{~km}$ race in a personal best time.

\section{DISCUSSION}

EHS is at the extreme end of the heat illness spectrum. It tends to occur when the metabolic heat production by muscles during activity outweighs the body's ability to transfer heat to its surroundings with an associated loss of thermoregulation. Subsequently, there is a rise in core temperature. This leads to thermal cellular damage producing cytokines that trigger a systemic inflammatory response syndrome and a pro-coagulant state. ${ }^{10}$ This is coupled with splanchnic vasoconstriction causing gut hypoperfusion and an increased permeability of the gut epithelium resulting in endo-toxin release. ${ }^{12}$ It is this combination, which leads to further loss of thermoregulation and lifethreatening complications of hyperkalaemia, circulatory collapse, multiorgan dysfunction and disseminated intravascular coagulation. ${ }^{10}$

Table 2 Shows observations at the medical tents for both runners

\begin{tabular}{|c|c|c|c|c|c|}
\hline & $\begin{array}{l}\text { Rectal temperature } \\
{ }^{\circ} \mathrm{C}\end{array}$ & $\mathbf{R R}$ & HR & Conscious level & Comments \\
\hline \multicolumn{6}{|c|}{ Twin A-collapsed at 19 miles $(30.5 \mathrm{~km})$} \\
\hline On arrival & 41.1 & 30 & 120 & Confused, responsive to verbal command & Cool peripheries and pale \\
\hline \multicolumn{6}{|c|}{ Cooling measures started } \\
\hline $15 \min$ & 40.2 & 24 & 122 & Confused & Developed muscle cramps \\
\hline $30 \mathrm{~min}$ & 38.2 & 28 & 104 & Alert & Cramps resolved \\
\hline $45 \min$ & 36.2 & 24 & 103 & Alert and orientated & \\
\hline $1 \mathrm{~h}$ & & 14 & 88 & Alert and orientated & Discharged from medical tent \\
\hline \multicolumn{6}{|c|}{ Twin B-collapsed at 21 miles $(33.7 \mathrm{~km})$} \\
\hline On arrival & 40.7 & 28 & 105 & Confused, responsive to verbal command & \\
\hline \multicolumn{6}{|c|}{ Cooling measures started } \\
\hline $15 \mathrm{~min}$ & 39.4 & 24 & 102 & Confused, responsive to verbal command & Developed muscle cramps in both legs \\
\hline $30 \mathrm{~min}$ & 38.2 & 19 & 87 & Alert & Cramps resolved \\
\hline $45 \mathrm{~min}$ & 36.9 & 18 & 80 & Alert and orientated & \\
\hline $1 \mathrm{~h}$ & & Not & & Alert and orientated & Discharged from medical tent \\
\hline
\end{tabular}


Data are limited on the incidence of EHS in endurance sport, particularly the reporting of non-fatal cases. The $11.5 \mathrm{~km}$ Falmouth Road Race in the USA, typically run in warm humid conditions (mean ambient temperature $23.3^{\circ} \mathrm{C}$ and average relative humidity 70\%), treats on average $10-20$ cases per 10000 entrants per year. ${ }^{3}$ In comparison, the Twin Cities Marathon (USA), run in cooler conditions (mean peak temperature $16^{\circ} \mathrm{C}$ and mean relative humidity 60\%) treats an average of 1 case of EHS per 10000 finishers, ${ }^{13}$ a 10 -fold difference. While humidity and WBGT are important factors, there are reports of EHS in cooler environments, often in shorter races, ${ }^{4} 513$ where the conditions are usually considered safer for running. The Great North Run (UK) in 2009 (13.1 miles $(21.1 \mathrm{~km})$-peak ambient temperature of $18^{\circ} \mathrm{C}$ ) reported 55 cases of EHS among the 55000 participants, ${ }^{4}$ an incidence rate similar to that observed at the Falmouth Road Race. Running intensity (directly linked to metabolic heat production) and individual predisposing factors have been suggested to influence the development of EHS.

\section{Predisposing factors and genetic link}

While a core temperature of $40^{\circ} \mathrm{C}$ and above makes up part of the definition of EHS, it is clear that individuals' heat intolerance can vary. This is highlighted by the fact that $15 \%$ of the 227 recreational runners completing a $15 \mathrm{~km}$ race had core temperatures of above $40^{\circ} \mathrm{C}$ without any neurological dysfunction. ${ }^{14} \mathrm{~A}$ number of predisposing factors to EHS have been suggested: current febrile illness, dehydration, increasing age, sleep deprivation, lack of heat acclimatisation, previous heatstroke and particular medications. ${ }^{6}{ }^{10}$ Neither twin had any intrinsic predisposing factors; however, the occurrence of EHS under similar extrinsic conditions suggests that a genetic predisposition to EHS may exist. It has been suggested that the variation of an individual's ability to tolerate torrid and humid environments may be attributed to the ability of their skeletal muscles to control the production and release of heat. ${ }^{15}$ There are strong biochemical, clinical and genetic similarities between EHS and the inherited skeletal muscle disorder, malignant hyperthermia $(\mathrm{MH}) .{ }^{10}$ Two-thirds of patients with $\mathrm{MH}$ show evidence of a mutation in the type 1 ryanodine receptor (RyR1), which plays a part in the release of calcium from the sarcoplasmic reticulum in the skeletal muscle. Further focus has been on the association between heat stroke and the calsequestrin 1 (CASQ1) gene located on chromosome one. ${ }^{16}$ CASQ1 is thought to have a role in the modulation skeletal muscle contraction through regulating calcium release in the sarcoplasmic reticulum. ${ }^{17}{ }^{18} \mathrm{Li}$ et $a l^{19}$ suggest an association between the single nucleotide polymorphism of CASQ1 and physiological parameters in 150 sufferers of heatstroke with focus on the N59D allele and elevated blood calcium levels.

Hopkins has previously highlighted the suggested genetic link between EHS and MH with several reports of patients with a history of EHS who have fulfilled the laboratory diagnostic criteria for susceptibility to $\mathrm{MH} .^{7}$ However, this relationship is debated, as data are limited to case series. More recently, Sagui et al retrospectively examined this link in 454 military participants who had suffered from EHS using the in vitro contracture test. They found that $45.6 \%$ of participants met the criteria for MH susceptibility. However, it was suggested that this high prevalence of the MH trait after EHS was related to a latent disturbance of calcium homoeostasis and they concluded that they could not determine whether patients with EHS have an increased risk of $\mathrm{MH}$ nor whether $\mathrm{MH}$ susceptibility is a risk factor for EHS. ${ }^{20}$
Further work is required in this area and specific genes related to EHS have yet to be identified. Alternatively, if EHS was predominantly genetic, why had it not occurred in previous races? Both twins had participated in marathon-like activities before and after this event with no heat-related problems. It is feasible that they are not necessarily more prone to EHS, but both share a common propensity to a comorbidity/predisposing factor. They followed the same course and were exposed to the same environmental conditions as other runners. Two potential influential factors, which differed from their previous races, were their role as race pacers and the additional wearing of the backpack with flag attachment.

\section{Role of pacing}

A runner's pacing strategy is determined by their underlying physiological regulation, which is based on continuous feedback and their prior experience. ${ }^{21}$ Running intensity is generally reduced when heat stress is perceived. Noakes describes this protective response as the central governor. ${ }^{22}$ Gonzalez-Alonso et $a l^{23}$ suggest that this is experienced as fatigue, which occurs when the core body temperature reaches $40^{\circ} \mathrm{C}$. It has been suggested that individuals can override this protective mechanism in competitive environments. Both athletes in this report remarked on the psychological pressure to maintain their pace time and recalled ignoring internal cues of fatigue. Unlike other runners, they are not able to vary their pace during the race and had to run at a set constant pace. The majority of EHS reports are in highly motivated athletes often in shorter races who are unwilling or unable to curtail their own work rate. ${ }^{4} 8{ }^{13}$ For example, the majority of EHS cases at the Great North Run were noted to be 'well prepared club runners' pushing for a personal best time. ${ }^{4}$ In short distance races $(5-20 \mathrm{~km})$, such as the Falmouth road race, athletes are more likely to attempt to run at higher intensities, producing a higher rate of metabolic heat, therefore increasing their risk of EHS. It has been suggested that exercise intensity has the greatest influence on the rate of increase of core temperature. ${ }^{3}$ In a marathon, runners will normally self-mediate their pace to prevent heat stress. However, the influence of pacers in a marathon may pressurise the runners to run at greater intensities. Roberts highlighted this in a case of a highly motivated runner who collapsed with EHS $10 \mathrm{~m}$ from the finish line of a marathon. He had been paced by a fresh runner for the last $16 \mathrm{~km}$ of the marathon. ${ }^{5}$ This questions the safety of race pacers for recreational athletes. Runners should be aware of EHS and reminded that if they are experiencing severe fatigue they must slow down. This will help their chances of avoiding EHS, especially in warmer conditions.

\section{Additional backpack}

Reports from American Football highlight the interaction between dress state and metabolic heat production. ${ }^{24}$ While the extra mass of backpack with flag attachment is small, there will have been some reduction in heat dissipation and increases in metabolic heat production. Perhaps, this tipped the balance for both runners, especially considering that pace times were well within their capabilities.

The explanation of why both twins developed EHS is likely to be multifactorial; however, the combination of the responsibilities of race pacing, the additional weight with resistance of the backpack and a genetic predisposition are likely to have played a part. Further work should focus on an accurate assessment of the incidence of EHS at a spectrum of endurance events, as well as the potential for advancements in gene technology to identify at-risk individuals. 


\section{Learning points}

- This case of monozygotic male twins who developed exertional heat stroke (EHS) in relatively cool conditions illustrates that this is a complex illness with a possible genetic predisposition, which is not exclusive to hot humid environments. It adds further to discussions regarding the genetic influence on the development of EHS.

- As race pacers, the twins were unable to curtail their work rate and overrode their internal cues of fatigue and heat stress to slow down. This is likely to have played a significant role in the development of EHS. Runners should be aware of EHS and reminded that if they are experiencing severe fatigue they must slow down. This will help their chances of avoiding EHS, especially in warmer conditions.

Acknowledgements The author would like to gratefully acknowledge Professor $S$ Sharma (Director of the Virgin London Marathon), the St John Ambulance and all staff involved in the patients' care.

Competing interests None declared.

Patient consent Obtained.

Provenance and peer review Not commissioned; externally peer reviewed.

\section{REFERENCES}

1 Pagnotta KD, Mazerolle SM, Casa DJ. Exertional heat stroke and emergency issues in high school sport. J Strength Cond Res 2010;24:1707-9.

2 Walter E, Kipps C, Venn R, et al. Exertional heat stroke. Position Statement 2014. UK: Faculty of Sport and Exercise Medicine. http://www.fsem.ac.uk/news/ position-statements/e/exertional-heat-stroke.aspx

3 DeMartini JK, Casa DJ, Belval LN, et al. Environmental conditions and the occurrence of exertional heat illnesses and exertional heat stroke at the Falmouth Road Race. J Athl Train 2014;49:478-85.

4 Hawes R, McMorran J, Vallis C. Exertional heat illness in half marathon runners: experiences of the Great North Run. Emerg Med J 2010;27:866-7.

5 Robertson B, Walter EJ. 'Cool Runnings': heat stroke in cold conditions. Emerg Med J 2010;27:387-8.
6 Casa DJ, Armstrong LE, Kenny GP, et al. Exertional heat stroke: new concepts regarding cause and care. Curr Sports Med Rep 2012;11:115-23.

7 Hopkins PM. Is there a link between malignant hyperthermia and exertional heat illness? Br J Sports Med 2007:41:283-4; discussion 284.

8 Armstrong LE, Casa DJ, Millard-Stafford M, et al. Exertional Heat illness during training and competition. Med Sci Sports Exerc 2007;39:556-72.

9 Heled Y, Rav-Acha M, Shani Y, et al. The golden hour' for heatstroke treatment. Mil Med 2004:169:184-6.

10 Walter E, Venn R, Stevenson T. Exertional heat stroke- the athlete's nemesis. JICS 2012;13:304-8.

11 Armstrong LE, Maresh CM, Crago AE, et al. Interpretation of aural temperatures during exercise, hyperthermia, and cooling therapy. Med Exerc Nutr Health 1994;3:9-16.

12 Hall DM, Buettner GR, Oberley LW, et al. Mechanisms of circulatory and intestinal barrier dysfunction during whole body hyperthermia. Am I Physiol Heart Circ Physiol 2001;280:509-21.

13 Roberts WO. A 12-yr profile of medical injury and illness for the Twin Cities Marathon. Med Sci Sports Exerc 2000;32:1549-55.

14 Veltmeijer MT Eijsvogels TM Thijssen DH, et al. Incidence and predictors of exertional hyperthermia after a $15-\mathrm{km}$ road race in cool environmental conditions. J Sci Med Sport 2015;18:333-7.

15 Kourtis N, Nikoletopoulou V, Tavernarakis N. Small heat-shock proteins protect from heat-stroke-associated neurodegeneration. Nature 2012;490:213-18.

16 Protasi F, Paolini C, Dainese M. Calsequestrin-1: a new candidate gene for malignant hyperthermia and exertional/environmental heat stroke. J Physiol (Lond) 2009;587:3095-100.

17 Lam KK, Cheng PY, Lee YM, et al. The role of heat shock protein 70 in the protective effect of Yc-1 on heat stroke rats. Eur J Pharmacol 2013:699:67-73.

18 MacLennan DH. Ca2+ signalling and muscle disease. Eur I Biochem 2000;267:5291-7.

19 Liu Y, Wang Y, Lin M. An association study of CASQ1 gene polymorphisms and heat stroke. Genomics Proteomics Bioinformatics 2014;12:127-32.

20 Sagui $E$, Montigon C, Abriat $A$, et al. Is there a link between exertional heat stroke and susceptibility to malignant hyperthermia? PLOS ONE 2015;10: e0135496.

21 Tucker R, Noakes TD. The physiological regulation of pacing strategy during exercise: a critical review. Br J Sports Med 2009;43:e1.

22 Noakes TD. The central governor model of exercise regulation applied to the marathon. Sports Med 2007;37:374-7.

23 Gonzalez-Alonso J, Teller C, Andersen S, et al. Influence of body temperature on the development of fatigue during prolonged exercise in the heat. J App Physiol 1999;86:1032-9.

24 Armstrong LE, Johnson EC, Casa DJ, et al. The American football uniform uncompensable heat stress and hyperthermic exhaustion. I Athl Train 2010;45:117-27.

Copyright 2016 BMJ Publishing Group. All rights reserved. For permission to reuse any of this content visit http://group.bmj.com/group/rights-licensing/permissions.

BMJ Case Report Fellows may re-use this article for personal use and teaching without any further permission.

Become a Fellow of BMJ Case Reports today and you can:

- Submit as many cases as you like

- Enjoy fast sympathetic peer review and rapid publication of accepted articles

- Access all the published articles

- Re-use any of the published material for personal use and teaching without further permission

For information on Institutional Fellowships contact consortiasales@bmjgroup.com

Visit casereports.bmj.com for more articles like this and to become a Fellow 